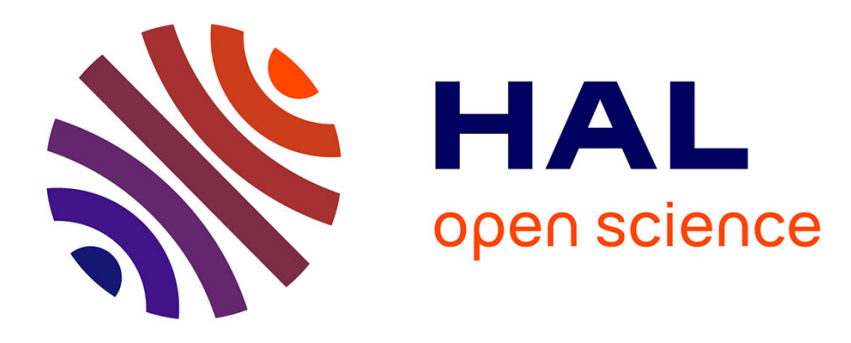

\title{
Physical activity and aerobic fitness in children with inherited cardiac diseases
}

Aymeric Boisson, Gregoire de La Villeon, Helena Huguet, Hamouda Abassi,

Jean Luc Pasquié, Kathleen Lavastre, Stefan Matecki, Sophie Guillaumont, Anne Requirand, Johanna Calderon, et al.

\section{To cite this version:}

Aymeric Boisson, Gregoire de La Villeon, Helena Huguet, Hamouda Abassi, Jean Luc Pasquié, et al.. Physical activity and aerobic fitness in children with inherited cardiac diseases. Archives of cardiovascular diseases, 2021, 10.1016/j.acvd.2021.07.004 . hal-03411440

\author{
HAL Id: hal-03411440 \\ https://hal.science/hal-03411440
}

Submitted on 2 Nov 2021

HAL is a multi-disciplinary open access archive for the deposit and dissemination of scientific research documents, whether they are published or not. The documents may come from teaching and research institutions in France or abroad, or from public or private research centers.
L'archive ouverte pluridisciplinaire HAL, est destinée au dépôt et à la diffusion de documents scientifiques de niveau recherche, publiés ou non, émanant des établissements d'enseignement et de recherche français ou étrangers, des laboratoires publics ou privés. 


\title{
Physical activity and aerobic fitness in children with inherited cardiac diseases ${ }^{\text {th }}$
}

\section{Activité physique chez l'enfant atteint de maladie cardiaque héréditaire}

\author{
Aymeric Boisson ${ }^{\mathrm{a}}$, Gregoire De La Villeon ${ }^{\mathrm{a}, \mathrm{b}}$, \\ Helena Huguet ${ }^{\mathrm{c}}$, Hamouda Abassi ${ }^{\mathrm{a}, \mathrm{d}}$, \\ Jean-Luc Pasquie ${ }^{a, d}$, Kathleen Lavastre ${ }^{a}$, \\ Stefan Matecki ${ }^{\mathrm{d}, \mathrm{e}}$, Sophie Guillaumont $\mathrm{a}^{\mathrm{a}, \mathrm{b}}$, \\ Anne Requirand $^{\mathrm{a}}$, Johanna Calderon ${ }^{\mathrm{a}, \mathrm{d}}$, \\ Pascal Amedrof,g,*
}

\footnotetext{
a Paediatric and Congenital Cardiology Department, M3C Regional Reference Centre, University Hospital, 34295 Montpellier, France

b Paediatric Cardiology and Rehabilitation Unit, Saint-Pierre Institute, 34250 Palavas-Les-Flots, France

c Clinical Research and Epidemiology Unit, CHU de Montpellier, University of Montpellier, 34295 Montpellier, France

d Inserm, PhyMedExp, CNRS, University of Montpellier, 34295 Montpellier, France

e Department of Physiology, CHU de Montpellier, 34295 Montpellier, France

${ }^{f}$ Department of Paediatric and Adult Congenital Cardiology, M3C National Reference Centre, Bordeaux University Hospital, 33604 Pessac, France

`Inserm, U1045, IHU Liryc, Bordeaux Cardio-Thoracic Research Centre, Electrophysiology and Heart Modelling Institute, University of Bordeaux, Fondation Bordeaux Université, 33604 Pessac, France
}

\section{KEYWORDS}

Physical activity; Inherited cardiac arrhythmia;

\section{Summary}

Background. - Because of sports and exercise restrictions, children with inherited cardiac disease are at risk of physical deconditioning. Guidelines on sports participation in cardiovascular disease have become less restrictive over time, but their real-life application and behavioural impact have seldom been evaluated in children.

Abbreviations: CHD, congenital heart disease; CPET, cardiopulmonary exercise test; ESC, European Society of Cardiology; RER, respiratory exchange ratio; $\mathrm{VO}_{2}$, oxygen uptake; WHO, World Health Organization.

Tweet: currently, most children with inherited cardiac arrhythmia or inherited cardiomyopathy have a good aerobic physical fitness and comply with the 2020 European Society of Cardiology guidelines on sports cardiology and exercise in cardiovascular disease.

* Corresponding author.

E-mail address: pascal.amedro@chu-bordeaux.fr (P. Amedro). 
Inherited cardiomyopathy; Paediatrics; Guidelines
Aims. - We aimed to evaluate adherence to the 2020 European Society of Cardiology guidelines on sports and exercise in children with inherited cardiac arrhythmia and inherited cardiomyopathy; we also sought to evaluate their aerobic fitness, and the behavioural impact of inherited cardiac diseases on physical activity in children.

Methods. - Children aged 6-18 years with inherited cardiomyopathy or inherited cardiac arrhythmia were eligible for this cross-sectional study. Clinical, demographic and qualitative data were analysed.

Results. - A total of 32 children were included in the study (mean age $12.7 \pm 3.5$ years). Most children $(\mathbf{8 1 . 3} \%$ ) complied with the 2020 European Society of Cardiology guidelines; they were physically active and had good overall aerobic fitness, with a mean peak oxygen uptake $\left(\mathrm{VO}_{2}\right)$ value of $36.5 \pm 8.0 \mathrm{~mL} / \mathrm{kg} / \mathrm{min}(84.0 \pm 17.2 \%$ of theoretical value). As a result of personal or parental behaviour, some children at risk of sudden cardiac death did not comply with the recommended upper limit of physical activity intensity, whereas others at low risk did not comply with the lower limit.

Conclusion. - Most children with inherited cardiac arrhythmia or inherited cardiomyopathy complied with current 2020 European Society of Cardiology guidelines on sports cardiology and exercise in cardiovascular disease.

\section{MOTS CLÉS}

Activité physique ; Arythmie cardiaque héréditaire ; Cardiomyopathie d'origine génétique ; Pédiatrie ; Recommandations

\section{Background}

Physical activity is known for its important benefits in terms of physical and mental health $[1,2]$. Based on the World Health Organization (WHO) guidelines, children and adolescents aged 5-17 years should undertake at least 60 minutes of moderate to vigorous physical activity daily [3]. Indeed, repeated physical activity and exercise help to prevent obesity, the prevalence of which has increased dramatically in the young [4]. A sedentary lifestyle and its consequences in the paediatric population currently represent a major public health issue, especially in children with pre-existing cardiac conditions [5-7].

Traditionally, congenital cardiac disorders are divided into three groups: congenital heart disease (CHD) for structural cardiac anomalies; inherited cardiac arrhythmias; and inherited cardiomyopathies. In the CHD population, early onset of physical deconditioning during childhood has been reported [8], even after successful cardiac surgical repair, and despite the absence of any sports restriction [9]. 
Parental and social barriers to physical activity in young people with CHD have been observed $[10,11]$, resulting in a rapid decrease in aerobic fitness and a lower health-related quality of life $[12,13]$. Therefore, most children with CHD are currently encouraged to follow the WHO guidelines on physical activity or, for severe conditions, to undergo cardiac rehabilitation programmes [14].

Data on the physical activity of children with inherited cardiac arrhythmia and inherited cardiomyopathy are scarce. Moreover, the risk of sudden cardiac death during exercise in these two specific groups often makes the balance between a precautionary approach and the promotion of physical activity difficult [15-19]. Nevertheless, the guidelines on sports participation in inherited cardiac arrhythmia or inherited cardiomyopathy have become progressively less restrictive over time [20-27]. In 2020, guidelines on sports participation and exercise in patients with cardiovascular disease from the European Society of Cardiology (ESC) supported the concept of shared decision making between patients, families and physicians in the promotion of physical activity in patients with inherited cardiac disorders [28].

However, these guidelines are mostly dedicated to adult patients, and their application in the paediatric population has not been evaluated. Importantly, few data are currently available on actual physical activity in children with inherited cardiac arrhythmia or inherited cardiomyopathy, in terms of both intensity capacity and aerobic fitness.

The primary aim of this study was to assess the level of adherence to the 2020 ESC guidelines on sports participation and exercise in children with inherited cardiomyopathy or inherited cardiac arrhythmia; we also sought to evaluate their aerobic fitness, and the behavioural impact of the disease on physical activity in daily life.

\section{Methods}

\section{Study design and population}

This observational cross-sectional study was carried out from May to December 2020 in two paediatric cardiology tertiary care hospitals, labeled as rare cardiac disease expert centres by national health authorities www.filiere-cardiogen.fr: the Paediatric and Congenital Cardiology Department of Montpellier University Hospital; and the Paediatric Cardiology and Rehabilitation Unit of the St-Pierre Institute in Palavas-Les-Flots, France. Patients were screened consecutively during their annual follow-up. All children aged from 6 to 18 years with inherited cardiomyopathy (e.g. hypertrophic cardiomyopathy, dilated cardiomyopathy or arrhythmogenic right ventricular cardiomyopathy) or inherited cardiac arrhythmia (e.g. long QT syndrome, Brugada syndrome or catecholaminergic polymorphic ventricular tachycardia), who underwent their routine paediatric follow-up during the study period, were eligible to participate in the study. Children with severe neurocognitive impairments, preventing them from understanding and/or answering the questions during the interview, were not included in the study. Children were ineligible if they had absolute contraindications for cardiopulmonary exercise test: fever; uncontrolled asthma; respiratory failure; acute myocarditis or pericarditis; uncontrolled arrhythmia; uncontrolled heart failure; acute pulmonary embolus or pulmonary infarction; and mental impairment leading to inability to cooperate.

The study complies with the declaration of Helsinki. Ethical approval was granted from Montpellier ethics committee (IRB-MPT_2020_03_202000385) before any data were collected. The study is registered on ClinicalTrials.gov (Identifier: NCT04650009). Informed consent was required from all parents or legal guardians, as well as the children's assent.

\section{Physical activity outcomes}

Patients' exercise intensity levels were categorized as low, medium or high, according to the 2020 ESC guidelines on sports participation and exercise in patients with cardiovascular disease [28]. Children who practiced less than 60 minutes per day of moderate-to-intense physical activity were considered to be physically inactive, as defined by the WHO guidelines [3]. The physical activity profile of each patient was assessed using the physical activity self-questionnaire from Ricci \& Gagnon [29], and was categorized as inactive (total score $<18$ ), active (total score $\geq 18$ and $\leq 35$ ) or very active (total score $>35$ ). This questionnaire has three summary scores: sedentary behaviour (one item); recreational physical activities (four items); and daily physical activities (four items). Each item uses a 5-point scale from 1 to 5 .

All interviewed children completed the questionnaires under the supervision of a paediatric cardiology research fellow (A. B.). The interview of the child and at least one

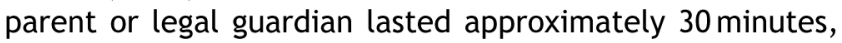
and was conducted in a quiet room, immediately after the annual paediatric cardiology consultation. If needed, the interview could also be conducted by videoconference. The clinical research team drafted a semistructured interview guide, with open-ended and closed-ended questions on physical activity (Table 1). The qualitative part of the interview focused on children's experiences, motivations and feelings regarding physical activity in the context of their cardiac condition. Once the child had answered the questionnaire, the parents were asked to answer the same questions.

\section{Aerobic fitness outcomes}

To assess aerobic fitness, children underwent a cardiopulmonary exercise test (CPET), using the same methodology as in our previous paediatric CPET studies [8,30,31]. The following variables were measured: maximum oxygen uptake $\left(\mathrm{VO}_{2 \mathrm{max}}\right)$; ventilator anaerobic threshold; ventilatory efficiency (VE $/ \mathrm{VCO}_{2}$ slope); oxygen uptake efficiency slope; maximum load; peak heart rate; and peak respiratory exchange ratio (RER). Peak $\mathrm{VO}_{2}$, ventilator anaerobic threshold and peak heart rate were normalized as percentage of predicted peak using normal values from Wasserman and Cooper $[1,32,33]$. The two investigating centres used the same CPET cycle ergometer protocol, in order to obtain a homogeneous incremental overall duration of between 8 and 12 minutes: a 1 -minute rest; a 3-minute warm-up (10-20 watts) in increments of 10,15 or 20 watts each minute, depending on the patient; a pedalling rate of $60-80$ 
Table 1 Physical activity interview guide.

Do you practice any sports, exercise or physical activity? If yes, name them

Do you practice competitive sports?

Do you know if exercise limitations exist in your cardiac condition?

How did you react when you discovered that you were limited in your physical activity?

Have you ever been in a situation where you would have liked to participate in a physical activity, but could not due to

your cardiac condition?

What did you feel in that moment?

Do you have extracurricular activities apart from physical activities?

If yes, describe your feeling and emotions regarding these activities

Do you have a medical sports certificate? Describe it if possible

Who gave you this medical sports certificate?

Do you have any current treatment for your cardiac condition?

What impact does your heart condition have on your physical activity?

Have you ever received advice or guidelines regarding therapeutic education during a consultation? (Drugs and

medications to avoid, warm-up before physical activity, life hygiene)

Would you be interested in a dedicated consultation on this subject?

Have you ever experienced any cardiac symptoms related to your cardiac condition? ${ }^{a}$

If yes, what did you feel at that moment?

Can you describe your feelings and emotion related to physical activity?

a Closed-ended questions.

revolutions per minute; a 3-minute active recovery (20 watts); and a 2-minute rest. The CPET was considered as maximal when the following criteria were reached: RER $\left(\mathrm{VCO}_{2} / \mathrm{VO}_{2}\right) \geq 1$; limit of the patient's tolerance despite verbal encouragement; plateau of $\mathrm{VO}_{2}\left(\mathrm{VO}_{2 \max }\right)$ despite increasing exercise intensity; and patient's inability to provide a minimum pedaling frequency of 60 revolutions per minute despite verbal encouragement. If the $\mathrm{VO}_{2 \max }$ did not reach the criteria for maximal effort, the peak $\mathrm{VO}_{2}$ was recorded, as is usual in paediatric CPET studies [34,35].

\section{Clinical outcomes}

The following clinical data were collected: demographic data (age, sex, time since diagnosis); anthropometric data; clinical cardiac diagnosis; age at diagnosis; time since diagnosis; circumstance of diagnosis; current treatment; presence of a cardiovascular event in the last 24 months; functional status (New York Heart Association classification); left ventricular ejection fraction; and presence and type of genetic mutation, as reported in medical records.

\section{Quantitative and qualitative data analyses}

Based on the interview data, patients were classified into two groups, according to level of adherence to the 2020 ESC guidelines on sports participation and exercise in patients with cardiovascular disease [28]: full adherence (e.g. strict compliance with the recommendations); or no adherence (e.g. practice of a non-recommended physical activity, in terms of type and/or intensity of exercise). Children from the "full-adherence" group were divided into three subgroups according to their level of maximum intensity exercise practice: (1) "maximum permitted level" group, if the child practiced exercise at the maximum intensity level authorized by the guidelines; (2) "lower level than permitted" group, if the child practiced exercise one intensity level down compared with the maximum intensity level authorized; and (3) "much lower level than permitted" group, if the child practiced exercise more than one intensity level down compared with the maximum intensity level authorized. In order to provide a double independent assessment, a blinded classification of patients in groups and subgroups was carried out by a senior sports cardiologist, who did not participate in the interview (G. D. L. V.).

Emotions and discourse of children and their parents were classified after the interview into three groups: positive (including joy, well-being, optimism and resilience); neutral (if participants expressed neutral discourse); and negative (including fear, sadness, frustration, disappointment and anger). Field notes were made during the interview. The examiner's notes and transcribed information were included for analysis. All data were anonymized by the principal investigator. Data were processed according to the thematic analysis method [36], and were collected in Excel spreadsheets.

\section{Statistical analyses}

The study population is described using means and standard deviations for quantitative variables and frequencies for qualitative variables. Continuous variable distributions were tested using the Shapiro-Wilk test. Quantitative variables were compared using Student's $t$-test when the distribution was Gaussian, and with the Mann-Whitney test otherwise. For qualitative variables, groups were compared using the $\mathrm{Chi}^{2}$ test or Fisher's exact test. For comparisons according to intensity of adherence to ESC guidelines, Holm's correction was applied for pairwise comparisons. Statistical significance was set at 0.05 , and analyses were performed using Statistical Analysis Systems Enterprise Guide, version 4.3 (SAS Institute, Cary, NC, USA). 
Table 2 Population characteristics.

\begin{tabular}{|c|c|}
\hline \multicolumn{2}{|l|}{ Inherited cardiac disease } \\
\hline Long QT syndrome & $18(56.3)$ \\
\hline Brugada syndrome & $1(3.1)$ \\
\hline ARVC & $2(6.2)$ \\
\hline Hypertrophic cardiomyopathy & $6(18.8)$ \\
\hline Dilated cardiomyopathy & $2(6.2)$ \\
\hline CPVT & $3(9.4)$ \\
\hline \multicolumn{2}{|l|}{ Sex } \\
\hline Male & $21(65.6)$ \\
\hline Female & $11(34.4)$ \\
\hline Age (years) & $12.7 \pm 3.5$ \\
\hline Age at diagnosis (years) & $6.6 \pm 5.2$ \\
\hline Body mass index $\left(\mathrm{kg} / \mathrm{m}^{2}\right)$ & $19.2 \pm 3.9$ \\
\hline Left ventricular ejection fraction (\%) & $67.3 \pm 6.6$ \\
\hline Cardiovascular event in the last 24 months $^{a}$ & $3(9.4)$ \\
\hline Identification of a genetic mutation & $29(90.6)$ \\
\hline \multicolumn{2}{|l|}{ Current treatment } \\
\hline Beta-blockers & $29(90.6)$ \\
\hline Implantable cardioverter defibrillator & $3(9.4)$ \\
\hline \multicolumn{2}{|l|}{ Circumstance of diagnosis } \\
\hline Familial genetic screening & $17(53.1)$ \\
\hline Symptoms & $14(43.8)$ \\
\hline Fortuitous diagnosis & $1(3.1)$ \\
\hline Physical inactivity (WHO guidelines) & $7(21.9)$ \\
\hline
\end{tabular}

ARVC: arrhythmogenic right ventricular cardiomyopathy; CPVT: catecholaminergic polymorphic ventricular tachycardia; WHO: World Health Organization. Data are expressed as number (\%) or mean \pm standard deviation.

a Cardiac arrhythmia, cardiac syncope, sudden cardiac arrest, chest pain at exertion.

\section{Results}

\section{Patient characteristics}

During the study period, 33 consecutive eligible patients were asked to participate after their regular consultation. After gaining consent from the parent or legal guardian, a total of 32 children were included in the study (mean age $12.7 \pm 3.5$ years; $65.6 \%$ male patients). One child and his family refused to participate because of a lack of time for the interview. Inclusions were distributed evenly between the two centres. Long QT syndrome represented the predominant cardiac disorder $(n=18)$. Most of the population was treated with beta-blockers $(n=29)$, whereas few had an implantable cardioverter defibrillator $(n=3)$. Regarding the circumstances of diagnosis, distribution was equitable between those diagnosed through familial genetic screening and those diagnosed after presenting cardiac symptoms related to their disease. Fortuitous diagnosis was exceptional. Few $(n=3)$ cardiac events during exercise were reported (e.g. non-severe moderate chest pain), and no sudden cardiac death or cardiac arrhythmia occurred in the last 24 months. No patients presented with heart failure symptoms at enrolment. Detailed population characteristics are presented in Table 2.

\section{Quantitative data on physical activity}

Most children with inherited cardiac arrhythmia or inherited cardiomyopathy enrolled in the study $(n=26,81.3 \%)$ complied with the current 2020 ESC guidelines on sports cardiology and exercise in patients with cardiovascular disease. From the physical activity self-questionnaire, the patients included in the study presented an active $(n=28)$ or inactive $(n=4)$ profile, with a mean overall score of $24.8 \pm 5.3$. In addition, in terms of amount of time being physically active, most enrolled children (78.1\%) complied with the WHO guidelines and were therefore not considered to be physically inactive. Children who complied with the WHO guidelines had a significantly higher score on the physical activity self-questionnaire than physically inactive children $(26.2 \pm 4.6$ vs. $19.7 \pm 4.8 ; P<0.01)$ (Table 3$)$.

In comparison with children complying with the 2020 ESC guidelines, children who did not follow them $(n=6$; mainly patients with catecholaminergic polymorphic ventricular tachycardia and arrhythmogenic right ventricular cardiomyopathy) showed a significantly lower maximum heart rate $(125.6 \pm 36.4$ vs. $152.9 \pm 24.0 ; P=0.03)$ and percentage of predicted heart rate $(61.2 \pm 16.9$ vs. $73.5 \pm 11.6 ; P=0.03)$ during exercise test. No other significant differences were observed between these two groups.

From the CPET results, aerobic fitness in children with inherited cardiomyopathy or inherited cardiac arrhythmia was good overall, with a mean peak $\mathrm{VO}_{2}$ value of $36.5 \pm 8.0 \mathrm{~mL} / \mathrm{kg} / \mathrm{min}\left(84.0 \pm 17.2 \%\right.$ of predicted peak $\left.\mathrm{VO}_{2}\right)$, and no evidence of physical deconditioning in the ventilatory variables (Table 3 ).

Among patients who followed the 2020 ESC guidelines $(n=26), 15$ children practiced exercise at the maximum intensity level authorized, seven children practiced exercise 
Table 3 Physical activity and aerobic fitness.

\begin{tabular}{|c|c|c|c|c|c|c|c|}
\hline \multirow[t]{3}{*}{ Variable } & \multirow{3}{*}{$\begin{array}{l}\text { Total } \\
(n=32)\end{array}$} & \multicolumn{3}{|c|}{2020 ESC guidelines } & \multicolumn{3}{|c|}{ WHO guidelines } \\
\hline & & \multirow{2}{*}{$\begin{array}{l}\text { Adherence } \\
(n=26)\end{array}$} & \multirow{2}{*}{$\begin{array}{l}\text { No adherence } \\
(n=6)\end{array}$} & \multirow[t]{2}{*}{$P$} & \multirow{2}{*}{$\frac{\text { Adherence }}{(n=25)}$} & \multirow{2}{*}{$\begin{array}{l}\text { No adherence } \\
(n=7)\end{array}$} & \multirow[t]{2}{*}{$P$} \\
\hline & & & & & & & \\
\hline Physical activity level & $24.8 \pm 5.3$ & $24.9 \pm 5.4$ & $24.5 \pm 5.8$ & 0.88 & $26.2 \pm 4.6$ & $19.7 \pm 4.8$ & $<0.01^{a}$ \\
\hline Peak $\mathrm{VO}_{2}(\mathrm{~mL} / \mathrm{kg} / \mathrm{min})$ & $36.5 \pm 8.0$ & $36.2 \pm 7.1$ & $38.0 \pm 13.2$ & 0.69 & $36.3 \pm 8.5$ & $37.5 \pm 5.9$ & 0.79 \\
\hline$\%$ predicted peak $\mathrm{VO}_{2}$ & $84.0 \pm 17.2$ & $84.1 \pm 15.4$ & $83.3 \pm 28.3$ & 0.93 & $84.3 \pm 18.1$ & $82.0 \pm 14.1$ & 0.81 \\
\hline VAT $(\mathrm{mL} / \mathrm{kg} / \mathrm{min})$ & $26.3 \pm 6.8$ & $26.5 \pm 6.3$ & $25.5 \pm 10.2$ & 0.80 & $26.1 \pm 6.8$ & $27.8 \pm 7.7$ & 0.66 \\
\hline$\%$ predicted VAT & $60.6 \pm 13.4$ & $61.1 \pm 12.2$ & $57.5 \pm 20.8$ & 0.63 & $60.4 \pm 12.8$ & $61.5 \pm 18.6$ & 0.88 \\
\hline VE/VCO ${ }_{2}$ slope & $30.8 \pm 5.9$ & $30.1 \pm 5.8$ & $35.3 \pm 6.1$ & 0.16 & $30.9 \pm 6.2$ & $30.3 \pm 5.0$ & 0.86 \\
\hline OUES & $1427 \pm 853$ & $1415 \pm 796$ & $1549 \pm 1766$ & 0.84 & $1398 \pm 844$ & $1605 \pm 1079$ & 0.71 \\
\hline OUES/kg & $32.8 \pm 15.8$ & $32.2 \pm 14.7$ & $38.3 \pm 31.8$ & 0.62 & $34.0 \pm 16.4$ & $25.5 \pm 10.6$ & 0.40 \\
\hline Peak RER & $1.14 \pm 0.10$ & $1.14 \pm 0.10$ & $1.11 \pm 0.08$ & 0.56 & $1.14 \pm 0.09$ & $1.16 \pm 0.15$ & 0.43 \\
\hline Peak HR (beats/min) & $147.8 \pm 28.0$ & $152.9 \pm 24.0$ & $125.6 \pm 36.4$ & $0.03^{\mathrm{a}}$ & $148.2 \pm 28.2$ & $146.0 \pm 30.5$ & 0.88 \\
\hline \% predicted HR & $71.2 \pm 13.3$ & $73.5 \pm 11.6$ & $61.2 \pm 16.9$ & $0.03^{\mathrm{a}}$ & $71.4 \pm 13.1$ & $70.4 \pm 15.6$ & 0.85 \\
\hline Maximum load (watts) & $118.9 \pm 57.7$ & $119.6 \pm 56.5$ & $116.0 \pm 69.7$ & 0.85 & $112.5 \pm 54.1$ & $147.0 \pm 70.9$ & 0.16 \\
\hline
\end{tabular}

ESC: European Society of Cardiology; HR: heart rate; OUES: oxygen uptake efficiency slope; peak $\mathrm{VO}_{2}$ : maximum oxygen uptake; RER: respiratory exchange ratio; VAT: ventilatory anaerobic threshold; $\mathrm{VE} / \mathrm{VCO}_{2}$ slope: ventilatory efficiency; WHO: World Health Organization. Data are expressed as mean \pm standard deviation.

a Significant $P$-value.

Table 4 Physical activity characteristics.

\begin{tabular}{|c|c|c|c|c|}
\hline & \multicolumn{4}{|c|}{ Adherence to 2020 ESC guidelines } \\
\hline & $\begin{array}{l}\text { Intensity at the } \\
\text { maximum level } \\
\text { permitted }\end{array}$ & $\begin{array}{l}\text { Intensity at a } \\
\text { lower level than } \\
\text { permitted }\end{array}$ & $\begin{array}{l}\text { Intensity at a } \\
\text { much lower level } \\
\text { than permitted }\end{array}$ & $P$ \\
\hline & $(n=15)$ & $(n=7)$ & $(n=4)$ & \\
\hline Physical activity level & $27.3 \pm 4.5$ & $23.7 \pm 3.5$ & $17.8 \pm 4.3$ & $<0.01^{\mathrm{a}}$ \\
\hline Peak $\mathrm{VO}_{2}(\mathrm{~mL} / \mathrm{kg} / \mathrm{min})$ & $35.7 \pm 4.5$ & $40.0 \pm 8.4$ & $31.8 \pm 9.9$ & 0.20 \\
\hline$\%$ predicted peak $\mathrm{VO}_{2}$ & $83.0 \pm 12.8$ & $93.3 \pm 16.3$ & $73.3 \pm 16.2$ & 0.12 \\
\hline VAT $(\mathrm{mL} / \mathrm{kg} / \mathrm{min})$ & $25.8 \pm 4.3$ & $29.8 \pm 7.3$ & $23.3 \pm 8.8$ & 0.25 \\
\hline$\%$ predicted VAT & $60.5 \pm 11.4$ & $66.7 \pm 8.2$ & $54.8 \pm 17.9$ & 0.32 \\
\hline $\mathrm{VE} / \mathrm{VCO}_{2}$ slope & $30.9 \pm 6.2$ & $29.3 \pm 7.1$ & $29.0 \pm 2.3$ & 0.93 \\
\hline OUES & $1493 \pm 737$ & $1466 \pm 793$ & $1156 \pm 1104$ & 0.67 \\
\hline OUES/kg & $34.9 \pm 13.4$ & $36.8 \pm 16.5$ & $19.9 \pm 11.5$ & 0.17 \\
\hline Peak RER & $1.15 \pm 0.08$ & $1.14 \pm 0.15$ & $1.14 \pm 0.10$ & 0.99 \\
\hline Peak HR (beats per minute) & $147.2 \pm 24.2$ & $165.3 \pm 21.3$ & $151.3 \pm 26.3$ & 0.33 \\
\hline$\%$ predicted HR & $70.8 \pm 11.3$ & $79.2 \pm 10.6$ & $73.0 \pm 14.0$ & 0.37 \\
\hline Maximum load (watts) & $111.7 \pm 48.9$ & $119.2 \pm 54.8$ & $143.8 \pm 86.7$ & 0.83 \\
\hline
\end{tabular}

at a lower level than authorized and four children practiced exercise at a much lower level than authorized. A total of 11 children $(34.4 \%)$ complied with the 2020 ESC guidelines but could perform physical activity at a higher intensity level. The three subgroups of actual over authorized exercise levels were significantly different in terms of physical activity self-questionnaire scores (Table 4).

\section{Qualitative data on physical activity}

Detailed data on patients' physical activities are presented in Table 5. Half of the interviewed children $(n=16)$ expressed positive emotions regarding physical activity in their daily life; for them, exercise was perceived as a source of pleasure and a factor of good global health, despite their 
Table 5 Patients' detailed physical activities.

\begin{tabular}{|c|c|c|c|c|}
\hline & Skill & Power & Mixed & Endurance \\
\hline \multirow{4}{*}{$\begin{array}{l}\text { Low } \\
\quad \text { intensity }\end{array}$} & Golf $(n=1)$ & Shot putting ${ }^{a}$ & Soccer $^{\mathrm{a}}(n=10)$ & Jogging \\
\hline & $\begin{array}{l}\text { Table tennis } \\
(n=2)\end{array}$ & Discus $^{a}$ & Basketballa $(n=3)$ & Long-distance walking \\
\hline & Shooting & $\begin{array}{l}\text { Alpine skiing }{ }^{a} \\
(n=1)\end{array}$ & Handballa $^{\mathrm{a}}(\boldsymbol{n}=5)$ & Swimming $^{\mathrm{a}}(n=7)$ \\
\hline & & & & Cycling $^{\mathrm{a}}(n=10)$ \\
\hline \multirow[t]{3}{*}{$\begin{array}{l}\text { Medium } \\
\text { intensity }\end{array}$} & Sailing & $\begin{array}{l}\text { Short-distance } \\
\text { running }(n=3)\end{array}$ & Volleyball $(n=1)$ & Speed walking \\
\hline & Yachting & Shot putting & Tennis (doubles) & Mid-/long-distance running \\
\hline & Equestrian $(n=1)$ & $\begin{array}{l}\text { Discus } \\
\text { Alpine skiing } \\
\text { Judo/karate } \\
(n=2)\end{array}$ & & Gymnastics $(n=2)$ \\
\hline \multirow[t]{10}{*}{$\begin{array}{l}\text { High } \\
\text { intensity }\end{array}$} & & $\begin{array}{l}\text { Weight lifting } \\
(n=2)\end{array}$ & Ice-hockey & Cycling (road) \\
\hline & & Wrestling & Hockey & Mid-/long-distance swimming \\
\hline & & Boxing $(n=3)$ & Climbing $(n=1)$ & Long-distance skating \\
\hline & & & Rugby $(n=2)$ & Pentathlon \\
\hline & & & Fencing & Athletics $(n=1)$ \\
\hline & & & Tennis (singles) $(n=1)$ & Rowing \\
\hline & & & Water polo & Canoeing \\
\hline & & & Soccer (competition) $(n=1)$ & Cross-country skiing \\
\hline & & & Basketball (competition) & Biathlon \\
\hline & & & Handball (competition) & Triathlon \\
\hline
\end{tabular}

heart disease. These patients stressed the social aspect of physical activity, as it allowed them to interact with peers during activities, even if they reported having to adapt the intensity of exercise ("I can still play football with my friends, as a goalkeeper for example"'). Resilience skills were frequently observed when analysing the discourse of those children (" it was difficult at first, but now that I understand why it's important, it does not bother me anymore'”). One third of the interviewed children practiced non-exercise related activities, such as music lessons or circus arts; they all expressed strong positive feelings about those activities, and placed them at the same level as exercise and sports in terms of a source of wellbeing, especially for children with strict sports restrictions ("music is all my life now, I like it even more than sports"').

Negative emotions were reported by $34 \%$ of children, who were mainly frustrated by limitations in terms of intensity of exercise, especially those who did not respect the ESC guidelines on sports cardiology and exercise in cardiovascular disease ("I can't exercise as much as I want to, I feel very limited"'). However, a feeling of fear related to physical activity in the context of their cardiac condition was not reported by any of the interviewed children ("I'm not afraid of practicing sports"').

When considering parents' reports, more than half (59\%) reported negative emotions regarding physical activity in the context of their child's cardiac condition. Fear was the predominant emotion reported by parents ('I'm always in fear that something may happen when I'm not there', ); they mainly expressed the need to supervise their child when practicing a physical activity, out of fear of sudden cardiac death or another serious clinical event. Most reported having set physical activity limits for their child, even if the guidelines and their physician were not as restrictive ("with such limitations, I feel safer"). Only 25\% of the interviewed parents reported positive emotions regarding their child's physical activity; according to them, controlled and supervised physical activity was still perceived as something beneficial for their children. Few children and parents $(n=5)$ expressed neutral emotions when reporting little to no impact on their daily life ("exercise and sports are not important to me, I am happy without it"').

A small number of patients $(n=5)$ and parents $(n=1)$ were not aware of exercise and sports restriction with regard to their child's cardiac disease, although they all respected the 2020 ESC guidelines "by chance".

Most families had received medical advice related to contraindicated drugs and medications or life hygiene. Half of the patients and families expressed the wish to receive structured patient therapeutic education dedicated to those topics.

\section{Discussion}

This study has reported, for the first time, the actual degree of implementation of the recent 2020 ESC guidelines on sports cardiology and exercise in a population of children 
with cardiovascular diseases. We found that a large majority of children with inherited cardiac arrhythmia or inherited cardiomyopathy complied with the 2020 ESC guidelines, and that only a minority was physically inactive. Furthermore, no serious cardiac events occurred in the last 24 months among enrolled children, which is consistent with recent studies suggesting that exercise-related events are rare in appropriately managed children with long QT syndrome and hypertrophic cardiomyopathy $[37,38]$. As this study was carried out concomitantly with the publication of the 2020 ESC guidelines, we may hypothesize that paediatric cardiologists had anticipated the recommendations by promoting physical activity at a safe level in children with cardiac conditions. Despite the absence of specific paediatric guidelines, these results are in line with the evolution of guidelines in sport cardiology and exercise in patients with cardiovascular disease in recent decades [20-27]. Nevertheless, our results contrast with recent public health data reporting that half of boys and more than two thirds of girls from the French general paediatric population did not follow the WHO guidelines regarding daily physical activity, and were considered to have a sedentary lifestyle [39]. In our study, analyses from the interviews suggest the existence of resilience skills in children with inherited cardiac disease, as classically described in many chronic diseases [40]. Added to changes in physician practice, this form of resilience may have contributed to promote physical activity in this population.

Of note, even if most children complied with the 2020 ESC guidelines on sports cardiology and exercise, those who did not follow them were among those at higher risk of sudden cardiac death during exercise. Indeed, all interviewed patients with catecholaminergic polymorphic ventricular tachycardia or arrhythmogenic right ventricular cardiomyopathy were found to practice high intensity exercise, even after their physicians advised them not to. This result may be explained by the absence of real physical disability during exercise, combined with strict exercise restrictions, in this group of patients. Yet, according to recent studies, approximately $30 \%$ of patients with catecholaminergic polymorphic ventricular tachycardia have a family history of sudden cardiac death before the age of 40 years $[41,42]$, and the mortality rate rises to $50 \%$ in severely affected and untreated patients [43]. In our study, the interviews showed that children who did not respect the 2020 ESC guidelines were mainly frustrated by the imposed intensity limitations for physical activities and were aware of the risks. To avoid any serious cardiac events in this selected population, it is necessary to build structured paediatric therapeutic education programmes promoting safe and adapted physical activity. Moreover, many children reported that non-exercise-related activities provided as much well-being as sports used to, which suggests good resilience skills. Indeed, mental health care to support the anticipation and management of their condition should be integrated into educational therapeutic programmes for children with inherited cardiac disorders.

In our study, children with inherited cardiomyopathy and inherited cardiac arrhythmia had good overall aerobic fitness, with no evidence of physical deconditioning. Data from exercise tests corroborated the results from the physical activity questionnaires and interviews, and the enrolled children did practice exercise and sports-related activities. No significant differences in aerobic fitness were reported when comparing children who complied with the 2020 ESC guidelines and those who did not, except for a lower maximum heart rate at exercise in children who did not follow the recommendations (i.e. those with catecholaminergic polymorphic ventricular tachycardia). Higher dosages of beta-blockers are used in these patients, which might explain this difference $[42,44]$.

Conversely, almost half of children who followed the 2020 ESC guidelines practiced physical activity at a lower level of intensity than permitted. From the interviews, parental barriers to physical activity were predominant in this group, as previously reported in children with CHD [11]. Future patient education programmes in children with inherited cardiac disorders should involve parental psychological follow-up to support adaptive coping strategies with regard to their child's condition. Finally, these children with inherited cardiac disorders are at risk of physical deconditioning, impaired health-related quality of life and additional cardiovascular burden in adulthood, as observed in CHD $[8,12,13,45]$. Thus, there is an urgent need to develop and implement holistic rehabilitation and educational programmes for children with inherited cardiac disorders and their families.

\section{Study limitations}

This study was performed in tertiary care centres and may not represent the overall population of children with inherited cardiac disease. However, in France, children with these cardiac disorders are usually followed in rare disease expert centres labelled by national health authorities (www.filiere.cardiogen.fr).

These preliminary results are limited by the study sample size; in addition, data on physical activity came from interviews and questionnaires, and no fitness tracker was used. Moreover, given the number of tests performed, marginal statistically significant differences should be interpreted with caution. Nevertheless, this pilot study was necessary to draft the current on-going QUALIMYOTYM trial, a controlled multicentre prospective study on health-related quality of life, physical activity and aerobic fitness in children with inherited cardiac arrhythmia or inherited cardiomyopathy [46].

\section{Conclusions}

This observational cross-sectional study has highlighted that most children with inherited cardiac arrhythmia or inherited cardiomyopathy comply with the current 2020 ESC guidelines on sports cardiology and exercise in patients with cardiovascular disease. Our results showed that these children were physically active and had good aerobic fitness. Nevertheless, because of personal or parental behaviour, some children at risk of sudden cardiac death did not comply with the upper limit of physical intensity, whereas others at low risk did not comply with the lower limit. 


\section{Funding}

This study was supported by the paediatric and congenital clinical research unit of Montpellier University Hospital and funded by a research grant from Cardiogen www. filiere-cardiogen. $\mathrm{fr}$.

\section{Acknowledgments}

We sincerely thank the families for their generous participation.

\section{Disclosure of interest}

The authors declare that they have no competing interest.

\section{References}

[1] Physical activity and cardiovascular health. NIH consensus development panel on physical activity and cardiovascular health. JAMA 1996;276:241-6.

[2] Fletcher GF, Balady G, Blair SN, et al. Statement on exercise: benefits and recommendations for physical activity programs for all Americans. A statement for health professionals by the committee on exercise and cardiac rehabilitation of the council on clinical cardiology, American Heart Association. Circulation 1996;94:857-62.

[3] Bull FC, Al-Ansari SS, Biddle S, et al. World Health Organization 2020 guidelines on physical activity and sedentary behaviour. Br J Sports Med 2020;54:1451-62.

[4] Praznoczy C, Lambert C, Pascal C. État des lieux de l'activité physique et de la sédentarité en France - Édition. Observatoire national de l'activité physique et de la sédentarité - Rapport; 2017. p. 130 [Available at: https://onaps.fr/actualisation-de-letat-des-lieux-de-lactivite -physique-et-de-la-sedentarite-en-france-edition $-2017 /]$.

[5] Karsenty C, Maury P, Blot-Souletie N, et al. The medical history of adults with complex congenital heart disease affects their social development and professional activity. Arch Cardiovasc Dis 2015;108:589-97.

[6] Papasavvas T, Alhashemi M, Micklewright D. Association between depressive symptoms and exercise capacity in patients with heart disease: a meta-analysis. J Cardiopulm Rehabil Prev 2017;37:239-49.

[7] Tamayo C, Manlhiot C, Patterson K, Lalani S, McCrindle BW. Longitudinal evaluation of the prevalence of overweight/obesity in children with congenital heart disease. Can J Cardiol 2015;31:117-23.

[8] Amedro P, Gavotto A, Guillaumont S, et al. Cardiopulmonary fitness in children with congenital heart diseases versus healthy children. Heart 2018;104:1026-36.

[9] Longmuir PE, Brothers JA, de Ferranti SD, et al. Promotion of physical activity for children and adults with congenital heart disease: a scientific statement from the American Heart Association. Circulation 2013;127:2147-59.

[10] Berg AE, Meyers LL, Dent KM, Rothwell EW, Everitt MD. Psychological impact of sports restriction in asymptomatic adolescents with hypertrophic cardiomyopathy, dilated cardiomyopathy, and long QT syndrome. Prog Pediatr Cardiol 2018;49:57-62.
[11] Moola F, Fusco C, Kirsh JA. The perceptions of caregivers toward physical activity and health in youth with congenital heart disease. Qual Health Res 2011;21:278-91.

[12] Amedro P, Dorka R, Moniotte S, et al. Quality of life of children with congenital heart diseases: a multicenter controlled crosssectional study. Pediatr Cardiol 2015;36:1588-601.

[13] Amedro P, Picot MC, Moniotte S, et al. Correlation between cardio-pulmonary exercise test variables and health-related quality of life among children with congenital heart diseases. Int J Cardiol 2016;203:1052-60.

[14] Amedro P, Gavotto A, Legendre A, et al. Impact of a centre and home-based cardiac rehabilitation program on the quality of life of teenagers and young adults with congenital heart disease: the QUALI-REHAB study rationale, design and methods. Int J Cardiol 2019;283:112-8.

[15] Corrado D, Basso C, Rizzoli G, Schiavon M, Thiene G. Does sports activity enhance the risk of sudden death in adolescents and young adults? J Am Coll Cardiol 2003;42:1959-63.

[16] Emery MS, Kovacs RJ. Sudden cardiac death in athletes. JACC Heart Fail 2018;6:30-40.

[17] Harmon KG, Asif IM, Maleszewski JJ, et al. Incidence, cause, and comparative frequency of sudden cardiac death in national collegiate athletic association athletes: a decade in review. Circulation 2015;132:10-9.

[18] Maron BJ, Doerer JJ, Haas TS, Tierney DM, Mueller FO. Sudden deaths in young competitive athletes: analysis of 1866 deaths in the United States, 1980-2006. Circulation 2009;119:1085-92.

[19] Solberg EE, Gjertsen F, Haugstad E, Kolsrud L. Sudden death in sports among young adults in Norway. Eur J Cardiovasc Prev Rehabil 2010;17:337-41.

[20] Ackerman MJ, Zipes DP, Kovacs RJ, Maron BJ. Eligibility and disqualification recommendations for competitive athletes with cardiovascular abnormalities: task force 10: the cardiac channelopathies: a scientific statement from the American Heart Association and American College of Cardiology. J Am Coll Cardiol 2015;66:2424-8.

[21] Hammond-Haley M, Patel RS, Providencia R, Lambiase PD. Exercise restrictions for patients with inherited cardiac conditions: current guidelines, challenges and limitations. Int J Cardiol 2016;209:234-41.

[22] Maron BJ, Chaitman BR, Ackerman MJ, et al. Recommendations for physical activity and recreational sports participation for young patients with genetic cardiovascular diseases. Circulation 2004;109:2807-16.

[23] Maron BJ, Udelson JE, Bonow RO, et al. Eligibility and disqualification recommendations for competitive athletes with cardiovascular abnormalities: task force 3: hypertrophic cardiomyopathy, arrhythmogenic right ventricular cardiomyopathy and other cardiomyopathies, and myocarditis: a scientific statement from the American Heart Association and American College of Cardiology. Circulation 2015;132:e273-80.

[24] Pelliccia A, Fagard R, Bjornstad HH, et al. Recommendations for competitive sports participation in athletes with cardiovascular disease: a consensus document from the Study Group of Sports Cardiology of the Working Group of Cardiac Rehabilitation and Exercise Physiology and the Working Group of Myocardial and Pericardial Diseases of the European Society of Cardiology. Eur Heart J 2005;26:1422-45.

[25] Pelliccia A, Solberg EE, Papadakis M, et al. Recommendations for participation in competitive and leisure time sport in athletes with cardiomyopathies, myocarditis, and pericarditis: position statement of the Sport Cardiology Section of the European Association of Preventive Cardiology (EAPC). Eur Heart $J$ 2019;40:19-33.

[26] Priori SG, Blomstrom-Lundqvist C, Mazzanti A, et al. 2015 ESC Guidelines for the management of patients with ventricular arrhythmias and the prevention of sudden cardiac death: the task force for the management of patients with ventricular 
arrhythmias and the prevention of sudden cardiac death of the European Society of Cardiology (ESC), endorsed by: Association for European Paediatric and Congenital Cardiology (AEPC). Eur Heart J 2015;36:2793-867.

[27] Zipes DP, Ackerman MJ, Estes 3rd NA, Grant AO, Myerburg RJ, Van Hare G. Task force 7: arrhythmias. J Am Coll Cardiol 2005;45:1354-63.

[28] Pelliccia A, Sharma S, Gati S, et al. 2020 ESC Guidelines on sports cardiology and exercise in patients with cardiovascular disease. Eur Heart J 2021;42:17-96.

[29] Vuillemin A, Denis G, Guillemin F, Jeandel C. A review of evaluation questionnaires for physical activity. Rev Epidemiol Sante Publique 1998;46:49-55.

[30] Abassi H, Huguet H, Picot MC, et al. Health-related quality of life in children with congenital heart disease aged 5 to 7 years: a multicentre controlled cross-sectional study. Health Qual Life Outcomes 2020;18:366.

[31] Gavotto A, Vandenberghe D, Abassi H, et al. Oxygen uptake efficiency slope: a reliable surrogate parameter for exercise capacity in healthy and cardiac children? Arch Dis Child 2020; 105:1167-74.

[32] Cooper DM, Berry C, Lamarra N, Wasserman K. Kinetics of oxygen uptake and heart rate at onset of exercise in children. $J$ Appl Physiol 1985;59:211-7.

[33] Cooper DM, Weiler-Ravell D, Whipp BJ, Wasserman K. Aerobic parameters of exercise as a function of body size during growth in children. J Appl Physiol Respir Environ Exerc Physiol 1984;56:628-34.

[34] Barker AR, Williams CA, Jones AM, Armstrong N. Establishing maximal oxygen uptake in young people during a ramp cycle test to exhaustion. Br J Sports Med 2011;45:498-503.

[35] Rowland TW, Cunningham LN. Oxygen uptake plateau during maximal treadmill exercise in children. Chest 1992;101:485-9.

[36] Vaismoradi $M$, Turunen $H$, Bondas T. Content analysis and thematic analysis: implications for conducting a qualitative descriptive study. Nurs Health Sci 2013;15:398-405.

[37] Chambers KD, Beausejour Ladouceur V, Alexander ME, et al. Cardiac events during competitive, recreational, and daily activities in children and adolescents with long QT syndrome. J Am Heart Assoc 2017;6:e005445.

[38] Saarel EV, Law I, Berul Cl, et al. Safety of sports for young patients with implantable cardioverter-defibrillators: longterm results of the multinational ICD sports registry. Circ Arrhythm Electrophysiol 2018;11:e006305.

[39] Verdot C, Salanave B, Deschamps V. Activité physique et sédentarité dans la population française. Situation en 2014-2016 et évolution depuis 2006-2007. Bull Epidemiol Hebd 2020;15:296-304.

[40] Cal SF, de Sá LR, Glustak ME, Santiago MB. Resilience in chronic diseases: a systematic review. Cogent Psychol 2015;2:1024928.

[41] Leenhardt A, Lucet V, Denjoy I, Grau F, Ngoc DD, Coumel P. Catecholaminergic polymorphic ventricular tachycardia in children. A 7-year follow-up of 21 patients. Circulation 1995;91:1512-9.

[42] Priori SG, Napolitano C, Memmi M, et al. Clinical and molecular characterization of patients with catecholaminergic polymorphic ventricular tachycardia. Circulation 2002;106:69-74.

[43] Priori SG, Wilde AA, Horie M, et al. HRS/EHRA/APHRS expert consensus statement on the diagnosis and management of patients with inherited primary arrhythmia syndromes: document endorsed by HRS, EHRA, and APHRS in May 2013 and by ACCF, AHA, PACES, and AEPC in June 2013. Heart Rhythm 2013;10:1932-63.

[44] Hayashi M, Denjoy I, Extramiana F, et al. Incidence and risk factors of arrhythmic events in catecholaminergic polymorphic ventricular tachycardia. Circulation 2009;119:2426-34.

[45] Saha P, Potiny P, Rigdon J, et al. Substantial cardiovascular morbidity in adults with lower-complexity congenital heart disease. Circulation 2019;139:1889-99.

[46] Amedro P, Werner O, Abassi H, et al. Health-related quality of life and physical activity in children with inherited cardiac arrhythmia or inherited cardiomyopathy: the prospective multicentre controlled QUALIMYORYTHM study rationale, design and methods. Health Qual Life Outcomes 2021;19:187. 